\title{
El buen vivir y el desarrollo desde la perspectiva del pueblo mayangna, Nicaragua
}

Good living and development from the Mayangna people perspective, Nicaragua

\author{
Elizabeth Salomón McCLean' \\ María Cristina Feliciano²
}

\section{Resumen}

Este breve ensayo es el resultado de una investigación sobre la conceptualización del buen vivir, "yamni yalahna/atinan lâni", vivir bien "yamni yalahnin" y el desarrollo "barakna lâni" en la cosmovisión del pueblo sumu-mayangna. Para entender mejor el concepto, se tomó en cuenta el pensar de los ancianos, jóvenes (varones y mujeres) y de personas profesionales. En el desarrollo del artículo se refleja las palabras de los personajes con quienes se realizó la conversación directa visitando las comunidades y comparaciones con la teoría occidental del buen vivir y el desarrollo. Así mismo, hace comparación con la teoría de los pueblos indígenas de otros países.

Palabra clave: buen vivir; vivir bien; desarrollo; pueblo mayangna.

\section{Abstract}

This brief essay is the result of an investigation on the good living "yamni yalahna / atinan lâni", living well "yamni yalahnin" and development "barakna lâni" conceptualizations, in the sumu-mayangna people worldview. To better understand the concept, the elderly, young people (men and women) and professional people thinking, was taken into account. In the development of the article, it is reflected the words of the characters with whom the direct conversation was made visiting the communities and comparisons with the western theory of good living and development. Likewise, it makes comparison with the theory of the indigenous peoples of other countries.

Keywords: good living; live good; developing; Mayangna people.

\section{Introducción}

Este breve ensayo tiene un carácter reflexivo para entender qué significan los términos "buen vivir o vivir bien" y el "Desarrollo" desde el pensar del pueblo sumu - mayangna, son términos nuevos que no tienen un concepto en sí, pero se pueden interpretar desde la forma de entender como pueblo "yamni yalahnin/ yamni atnin" o "buen vivir" y "Barakna lâni" o "desarrollo". Para este estudio se hizo entrevistas a jóvenes, adultos profesionales y comunitarios de Awastingni municipio de Waspam y en Mahalwas, municipio de las Minas Bonanza, comparando con los paradigmas occidentales.

\footnotetext{
1 Máster en Planificación y Desarrollo Regional con Identidad. Coordinadora del Instituto de Promoción e Investigación Lingüística y Revitalización Cultural de la Universidad de las Regiones Autónomas de la Costa Caribe Nicaragüense-Recinto Universitario-Bilwi. Correo: elisalomon12@yahoo.es

2 Máster en Planificación y Desarrollo Regional con Identidad. Coordinadora de Planificación de la Universidad de las Regiones Autónomas de la Costa Caribe Nicaragüense-Recinto Universitario Las Minas. Correo: planificacion.lasminas@uraccan.edu.ni
}

Recibido: 20/06/2018 - Aprobado: 24/01/2019 
El término "buen vivir o vivir bien", desde otra mirada que no es perteneciente a un pueblo originario, es tener dinero, recibir una educación digna, tener una buena casa, aprovechar los recursos naturales como el bosque, recursos marinos, la tierra para obtener el dinero. Tener control sobre los pueblos originarios, extraer los recursos naturales de manera descontrolada.

Primero hay que estar bien. "Saber vivir implica estar en armonía con uno mismo; "estar bien" o "sumanqaña” y luego, saber relacionarse o convivir con todas las formas de existencia.

El desarrollo definido como: “...un proceso de ampliación de la gama de opciones y de posibilidades que se le ofrece a cada quien." También es definido "como opciones y capacidades individuales de las personas para construir en libertad su propio proyecto de vida".

El desarrollo humano tiene dos caras que se requieren mutuamente: el aumento de capacidades de las personas para ejercer su libertad y la reacción de un entorno social que haga posible ese aumento y asegure la libertad de optar. En suma, se trata de las condiciones políticas, jurídicas, sociales, económicas y culturales para el ejercicio real del derecho a definirse y construir el tipo de vida deseado.

Para obtener una buena definición desde el pensamiento mayangna, seleccionamos jóvenes entre mujeres y varones, así mismo hombres y mujeres profesionales y comunitarios. Cada uno de estos grupos expresaron cómo entienden como personas.

\section{Desarrollo}

En esta sección, se aborda el concepto que define algunos paradigmas occidentales, la citas del pensar del pueblo sumu - mayangna de los participantes de las dos comunidades. En primer momento se describe el pensar sobre el significado de "buen vivir" después sobre el "desarrollo".

\subsection{Concepto de buen vivir}

Algunos jóvenes y un anciano expresan que para ellos el buen vivir es tener limpia la comunidad, trabajar en armonía y bien coordinados con las diferentes organizaciones estructurales que hay dentro la comunidad, es decir, con todos los líderes deben pensar por el bienestar de su pueblo. También el buen vivir es tener respeto a la madre tierra, conservar los recursos de la naturaleza, saber administrar, controlando todo lo que les rodea. Así también, el buen vivir es tener suficiente alimento para consumo ya que sin alimento no es un buen vivir o vivir bien dentro la familia y en la comunidad, como pueblo deben vivir en armonía con sus hermanos y hermanas.

Así mismo, se puede decir de un buen vivir cuando haya respeto a Dios del viento, dueño del cerro, dueño del duende, dueño del río que es la sirena, espíritus de los muertos, montañas, dueños de los animales salvajes llamado Pauka, toda la naturaleza está bajo un mandato de un Dios poderoso que lo controla y como pueblo creemos en Asangbâ, desde las épocas ancestral ha sido el dios de los indígenas mayangna, como universal, por eso ha habido un respeto singular hacia la naturaleza. Desde muy antiguo la forma de caza y pesca, la extracción de madera era bajo un control muy estricto hasta incluso tenían que pedir la cantidad de animales que quieren cazar en un determinado tiempo y si abusaban ese acuerdo, eran castigados, el castigo consistía en que se enfermaban y era posible hasta morir, por eso los ancestros respetaban las normas. Así el término de "buen vivir" le satisfacía vivir en armonía con la naturaleza.

También si hay paz y tranquilidad podemos decir que estamos o que tenemos el buen vivir. Para el pueblo mayangna "yamni yalahnin", no es destruir el medio en que estamos sino respetar la diversidad, porque de ellos depende la vida, en ellas está la medicina, laboratorio de prácticas, hoteles, la comida, la carnicería, la empresa, la diversión y balnearios. 


\subsection{Concepto del desarrollo}

Ahora veamos qué expresan sobre el significado de "barakna lâni" que es el desarrollo. El desarrollo es mejorar la calidad de vida, partiendo de diferentes ámbitos como: salud, educación, cultura y deporte, especialmente en el hogar y en la sociedad. Además, siempre el desarrollo debe partir desde abajo, es decir desde la comunidad.

Un anciano, expresa que el desarrollo es trabajar en la crianza de animales para consumo y venta para suplementar otras necesidades básicas de su familia. Para otro joven el desarrollo es hacer una cosa buena en la comunidad, gestionar programas que hagan progresos, así mismo que los lideres de la comunidad hagan cambios con los fondos que consiguen de la extracción de recursos naturales, también se puede decir de construir hospedajes como fuente de ingreso para la comunidad, un desarrollo es tener medio de transporte terrestre, eso es un desarrollo.

En cambio, para las mujeres hablar de desarrollo es tener acceso a la educación, prepararse profesionalmente para ayudar a la comunidad fortaleciendo nuestra cultura. Así mismo, se puede decir de desarrollo cuando haya un puesto de salud abastecido de medicamento y también un espacio para diversión de los jóvenes y niños, es decir un estadio para que nuestra juventud en vez de andar en otras cosas pueda jugar.

El desarrollo es un término que nace desde la visión de los capitalistas para incrementar la economía, mientras para el pueblo es progresar manejando o administrando de una forma transparente sus recursos naturales.

Parar el pueblo mayangna para lograr un desarrollo deben de trabajar en armonía pensando por un interés en común. Sin división así podrán velar por los recursos naturales, administrando los bienes y recursos de la comunidad.

\section{Conclusión}

En conclusión, el pueblo mayangna considera que el termino buen vivir es la convivencia armónica con los hermanos, hermanas de la comunidad, y tener una buena relación con la madre tierra teniendo un compromiso y respeto a la madre tierra.

Para el pueblo mayangna los dos conceptos son dependientes de la noción de respeto y compromiso con la Madre Tierra. Tanto los mayangnas como otros pueblos Indígenas afirman que el buen vivir es la práctica de vivir en armonía y equilibrio con todo lo que rodea al individuo, su familia, su comunidad y el medio ambiente del que forma parte, ya que de ella obtiene su desarrollo social y económicos. Los jóvenes, mujeres y varones, tienen una visión occidental, aunque en el fondo hay quienes aún sostienen que el buen vivir consiste en estar en armonía con la naturaleza y tener respeto a la Madre Tierra. Se considera que es necesario profundizar el estudio enfocando en diferentes aspectos, desde la mujer anciana, relacionar el buen vivir con la violencia.

\section{Lista de referencias}

Méndez Quintana, D. (2000). Una mirada al concepto desarrollo. Managua Nicaragua.

Huanacuni Mamani, F. (2010). Buen Vivir / Vivir Bien Filosofía, políticas, estrategias y experiencias regionales andinas. Perú. 
Maldonado, L. (2005). Desarrollo con Identidad. Ecuador. Recuperado de: www.monografias.com/trabajos88/ecuador-y-buen-vivir/ecuador-y-buen-vivir.shtml\#ixzz2FcNWY2il

Guevara C, Ana P.; Antonio L, Hidalgo C; José A. Domínguez G. (2014). El pensamiento sobre el buen vivir. Entre Indigenismo, el socialismo y el pos desarrollismo.

PNUD. (2005). Informe de Desarrollo Humano. 